\title{
MODELING NATIONAL INNOVATION SYSTEM ENABLED BY KNOWLEDGE MANAGEMENT
}

\section{Mei-Tai CHU' ${ }^{1}$, Sedigheh REZAEIAN FARDOEI ${ }^{2}$, Hasan FALLAH ${ }^{3}$, Sepehr GHAZINOORY ${ }^{4}$, Alireza ALIAHMADI ${ }^{5}$}

${ }^{1}$ Department of Management, La Trobe Business School, Faculty of Business, Economics and Law, La Trobe University, Bundoora, Victoria, 3086, Australia

${ }^{2,3}$ Department of Industrial Engineering, Faculty of Engineering,

Payame Noor University, PO BOX 19395-3697, Tehran, Iran

${ }^{4}$ Department of Industrial Engineering, Faculty of Information Technology, Tarbiat Modares University, Jalal Ale Ahmad Highway, Tehran, Iran

${ }^{5}$ Department of Industrial Engeenring, Faculty of Engineering,

Science and Technology University, Resalat, Tehran, Iran

E-mails:1'm.chu@latrobe.edu.au; ${ }^{2}$ srezaiian@gmail.com (correspondingauthor);

3fallah@pnu.ac.ir; ${ }^{4}$ ghazinoory@yahoo.com; 5aaliahmadi@yahoo.com;

Received 15 August 2012; accepted 02 January 2013

\begin{abstract}
The main objective of this paper is to explore the model of how knowledge management functions enables national innovation system. To achieve the objectives of the study, a conceptual framework is proposed and described, then the systemic analysis is undertaken. Path coefficient and t-value are also used to measure the relationships among chosen variables. A great number of sources are used to collect data, including questionnaires, interviews, observations, and literature review. The achievements of the study demonstrate 10 distinctive national innovation system performance dimensions and the relationship with knowledge management functions. The first layer includes explicit knowledge, while the second layer deals with tacit knowledge. Both of two layers link to a complete knowledge management functions and processes: explicit knowledge building, explicit knowledge gathering, explicit knowledge distributing, explicit knowledge reusing, tacit knowledge capturing, tacit knowledge sharing tacit knowledge disseminating, tacit knowledge innovating; whereas the third layer includes NIS enablers items or performance dimension of national innovation system: quality, effectiveness, quantity, codification, structure, efficiency, internalization, expertise, effectiveness.
\end{abstract}

Keywords: national innovation system (NIS), knowledge management (KM), knowledge management function, national innovation system performance, knowledge flowing, knowledge economy.

JEL Classification: D80, D89, O32, O39. 


\section{Introduction}

In 1987, Freeman proposed the concept of "national innovation system" (NIS). From then on, academic research on NIS has been flourishing along with studies about knowledge based economy and knowledge management in NIS. Indeed, the current industrialized countries have specific processes to focus on the creation of knowledge-based economies (KBE) in their societies and industries (OECD 1996; DTI 1998). Hence the generation of new knowledge, technological progress and innovation are determining factors in economic growth. In this regard, the national innovation systems act through the introduction of knowledge in the economy (and in society in general). The world economy is becoming ever more dependent on creating, distributing, and using knowledge. Even quite a few existing work have focused on contributing a new perspective to the study of national innovation in the area of knowledge-based economies using NIS approach (OECD 1996; Freeman 1987; Lundvall 2006; Nelson, Rosenberg 1993; Patel, Pavitt 1994; Hekkert et al. 2011; Cuiping 2008; Helios, Hidalgo 2008; Xiwei, Stößlein 2010). There is little research that compares approaches by discussing an effective KM framework as the central theme. Thus, one aim of this paper is to integrate systems of innovation studies and knowledge management functions to provide a better understanding of the NIS knowledge point of view.

Section 1 examines the recent studies of systems of innovation from knowledge and knowledge management perspective. Three approaches are identified: (a) innovation and knowledge management, (b) innovations systems and knowledge management, (c) how KM enables NIS? Our research offers definitions followed by a discussion of elements, units and dimensions of analysis, and conceptual frameworks that shows how knowledge management can enables NIS. Hence, in Section 2, we discuss theoretical framework and hypotheses and conceptual model. Section 3 raises research methodology and data collection with data analysis. Finally, results and paths between knowledge management functions or activities and NIS performance dimensions are suggested, discussed and concluded for show how could be enabled systems of innovation by knowledge management. Hence, the present paper contributes to the nascent body of research on modeling how KM functions enable NIS.

\section{Theoretical background}

The first section, "Theoretical background", provides an extensive literature review on relationship between knowledge management and national innovation system.

\subsection{NIS}

This section describes the national innovation system approach. However, since the national innovation system approach is not one single theory, because different authors have had different approaches. Freeman (1987) focused on the NIS of Japan, particularly the role and organization of government policy, business sectors, education and training, and related social innovation. Another early contribution has come from Nelson, Winter (1988) and since then the studies have been continued by several scholars like: Hekkert et al. (2011), Thompson et al. (2014) and so on. 
The researches of National Innovation System pay attention to knowledge production, dissemination and application at the national level. On the other hand, an emphasis of the OECD framework is the concept of the "distribution power" of a NIS (David, Foray 1994). However, it should be kept in mind that the distinction between the creation and the distribution of knowledge is mainly analytical. In reality, in advanced countries the application of old knowledge is often closely connected to the creation of new knowledge (Cohen, Levinthal 1989). Mytelka, Smith (2002) proposed a NIS based definitions developed by Lundvall (2006) and Nelson and Rosenberg (1993). They addressed that innovation is an interactive process in which enterprises interact with each other and are supported by institutions and a wide range of organizations that play a key role in bringing new products, new processes and new forms of organization into economic use. This approach emphasizes that the flows of knowledge and information that are at the heart of an innovation system, which is multidirectional and links a wider set of actors than those located along the value chain. From learning perspective, if there is one attribute that characterizes a successful NIS, it is learning.

Therefore learning, knowledge creation, knowledge capture and mutual contacts in the structure of the national innovation system have been discussed in the NIS concepts and definitions.

\section{2. $K M$ concept and innovation aspect of $K M$}

Knowledge management is increasingly becoming an integral business function for many firms, as they realize that organizational competitiveness hinges on the effective management of intellectual resources (Grover, Davenport 2001; Randeree 2006). There is an extensive body of literature on knowledge management dealing with important issues, such as the type and conceptualization of knowledge (Nonaka, Takeuchi 1995; Durant-Law 2006; Jafari et al. 2009).

Some studies have tackled knowledge creation (Nonaka, Takeuchi 1995; Aramburu et al. 2006) and knowledge transfer processes (Nonaka, Takeuchi 1995; Zander, Kogut 1995; Guzman, Wilson 2005); few have explored knowledge protection (Randeree 2006) and knowledge retention processes (Scalzo 2006). Moreover, several studies have been done on innovation (Coombs, Hull 1998; Jolivet et al. 2003).

The crucial viewpoints of those representative literatures include: knowledge is realized as the foundation of innovation and effective knowledge management can enhance the using and the efficiency of the allocation of innovation resources for the national innovation system.

\subsection{Enablers from KM to facilitate NIS}

This section aims to discuss which enablers from KM system can facilitate the operation of NIS. The first part outlines the concept of NIS from the viewpoint of KM. The second part examines which KM functions can impact on NIS performance. The main aim of this part is to reveal more clearly the research gap that assumes linking KM issues to the NIS discourse. 


\subsubsection{NIS from KM perspective}

In the KM and NIS field of study the scholars (Carayannis et al. 2000; Chuanqi 2001; Cuiping 2008; Amidon 1997; Foray 1994; Helios, Hidalgo 2008; Xiwei, Stößlein 2010; Goh 2004; Liu 2005; Li 2009) have done researches from following aspects: Peng (2003) took charge of the State Natural Sciences Foundation project "information guarantee for scientific research and its development", which puts forward a systematic information guarantee theory. In relation studies about information guarantee, knowledge innovation and innovation system, a common consent is that information guarantee system is one of sub-systems of innovation system, which is characterized by integrity, amalgamation, centrality, supportability and attribute of resources. At the same time, innovation system realizes the functions of information regulating, communicating, disseminating and information service (Wang, Kong 2004; Zhao 2003). Meng (2005), Wang (2002), Xiao (2004), Helina (2008) propose an innovation-oriented information guarantee system conception and discuss its constitution frame as well as its essential factors. In Hu et al. (2008) scholars put forward their issue how to construct an integrated information service system for NIS, which provides basis for governance advancement. Other scholar believe KM in NIS is in fact, production and knowledge dissemination of knowledge, knowledge creativity of the application of the network system and knowledge innovation through the production, dissemination and application of the whole process. On this basis, a state innovation system can be divided into four subsystem: knowledge innovation system and technological innovation system and knowledge dissemination of information systems and applications systems.

\subsubsection{How KM functions affect on NIS performance?}

Knowledge capacity and its distribution, scale and efficiency of knowledge transmission, the ability of knowledge collection and processing immediately influence national innovation system's structure and the operating efficiency (Zhao et al. 2004).

From knowledge management aspect, the knowledge sharing and allocation efficiency of IS is influenced by four complications: knowledge characteristics, main bodies work efficiency, knowledge link and the relevant policy system. It also proposes knowledge management implementation way and methods including to increase system's internal knowledge capacity, to speed up system's knowledge link and flow, to enhance the breadth and the intensity of knowledge link to optimize the policy environment for knowledge transmission and so on (Liu, Shi 2004).

Liu (2003) raises his issue that knowledge flowing will cause innovation's evolution, the knowledge transmission process is going along with the information communication process simultaneously, different information communication way leads to different levels of knowledge flowing efficiency. The core of Innovation System relies on the high-speed flow of innovation information and booming technology transaction among main bodies on different levels within the system. Embarking from specific purposes and demands of the main bodies, the scholars have analyzed and appraised the barriers and bottleneck in the process of knowledge creation, transmission and application (Zhao et al. 2004). 
And then, Li (2003) presents that innovation overall achievements can be enhanced by improving main bodies' composing as well as the correlation among them. The key job for innovation system construction rests with how to boost knowledge flowing among innovation main bodies. Knowledge alliance is treated as an effective organizational pattern in one innovation system ( $\mathrm{Li} 2003$ ). Moreover the investigations show knowledge management is efficiency and effectiveness guarantee of NIS. On the other side, researchers knowledge began to attach importance to the national level in the production, dissemination and application of information and knowledge and innovation of the national innovation system and its role in the theoretical level and experiential terms of the preliminary study. Also as mentioned before, knowledge to innovate, knowledge and distribution, knowledge of the scale and efficiency, knowledge, collecting and processing power is directly affects the state innovation system of the operating efficiency. Liu and Shi (2004) from the perspective of knowledge and analysis of the national innovation system, discussed about: the knowledge of the main features, efficiency, knowledge and system linking environmental to a state innovation system knowledge sharing in the efficiency and configure the effects, in a state innovation system of knowledge within administration of the channels and methods, including: increase the capacity of the system of knowledge, knowledge of the system within the link the velocity of information link scope and strength and improving the knowledge flow of the system of the environment.

Moreover, based on the literature, the effect of knowledge diffusion, knowledge configuration and knowledge share in the national innovation system, includes four aspects: 1) the characteristics of knowledge; 2) the efficiency of actors; 3) knowledge links, the collaboration and integration between actors; 4) the institutional environment to integrate all the various elements (Liu, Shi 2004; Meng 2005; Carayannis et al. 2000; Chuanqi 2001; Cohen, Levintal 1989; Cuiping 2008; Amidon 1997; Helios, Hidalgo 2008; Xiwei, Stößlein 2010; Goh 2004; Liu, 2005; Li 2009). Therefore in summery, we surveyed the existing literature on national innovation systems (NISs) and KM to explore the implications for developing a conceptual model.

By summing up, the authors found the area of research has just begun, in a state innovation system in the knowledge of the current mechanism to produce and disseminate information and knowledge of the mechanism of the research for lack of knowledge and information service network, managing knowledge flow, the structure and mode of motion governing the problems have yet to be to further explore. The most important thing is the concept of KM functions and explicit and implicit KM and NIS performance have not been addressed in an integrated and systematic approach in the literature.

\section{Theoretical framework}

The review of relationship between KM and NIS clearly showed that NIS performance dimensions are be enabled by KM. Although much has been said, there are several questions still unanswered. The majority of the studies carried out on knowledge management processes and innovation have explored large rather than knowledge management 
functions in NIS. Much remains to be understood concerning the specific knowledgemanagement processes and NIS. Indeed, the way KM enables NIS (Carayannis et al. 2000; Chuanqi 2001; Cohen, Levintal 1989; Cuiping 2008; Amidon 1997; Foray 1994; Helios, Hidalgo 2008; Xiwei, Stößlein 2010; Goh 2004; Liu 2005; Li 2009) has not yet been fully understood by a comprehensive and systematic model.

Therefore, base on the mentioned findings, the author found some shortcomings that were not addressed in previous paper results for e.g. there is no modeling to show how KM functions enables NIS and influence on its performance in systematic approach. Dimensions and factors of NIS performance measurement were organized in the Table 1.

Table 1. Dimensions and factors of NIS performance measurement

\begin{tabular}{ll}
\hline NIS performance measurement dimensions & \multicolumn{1}{c}{ Citation source } \\
\hline KM and quantity of NIS. & Liu (2005), Cuiping (2008) \\
\hline KM and codification of knowledge in NIS. & Liu (2005), Li (2009), Cuiping (2008) \\
\hline KM and structure of NIS. & Li (2009), Xiwei, Stößlein (2010) \\
\hline KM and efficiency of NIS. & Li (2009), Liu (2005), Lundvall (2006), \\
& Cuiping (2008) \\
\hline KM and quality of NIS. & Liu (2005), Lundvall (2006), Cuiping (2008) \\
\hline KM and knowledge internalization in NIS. & Lundvall (2006), Laursen (1995) \\
\hline KM and expertise in NIS. & Lundvall (2006), Laursen (1995) \\
\hline KM and effectiveness of NIS. & Liu (2005), Lundvall (2006), Li (2009), \\
& Cuiping (2008) \\
\hline
\end{tabular}

\subsection{Hypotheses of the model}

In this activity, we surveyed the existing literature on NIS and KM to explore the implications for developing a conceptual model. The model integrates the main components of the aforementioned KM process and functions base on Newman and Conrod (1999) and NIS performance dimensions into a comprehensive one composed of 8 paths which has been illustrated in Figure 1.

As mentioned before Figure 1 shows the research model of the paper, which the hypotheses have been defined base on the structural model. Hypotheses are base on the path analysis according to the relationship between the components (explored from literature) which the model has been built based on them. According to the related literature, the hypotheses have been built for relationship between components of the model (Table 2)

\subsection{The conceptual model}

The conceptual model is composed of 8 paths as framework which has been illustrated in Figure 1.

Considering how knowledge management supports NIS as illustrated in Figure 1, two dimensions are widely adopted to differentiate the focus and highlight. They are ex- 
Table 2. Hypotheses of the model

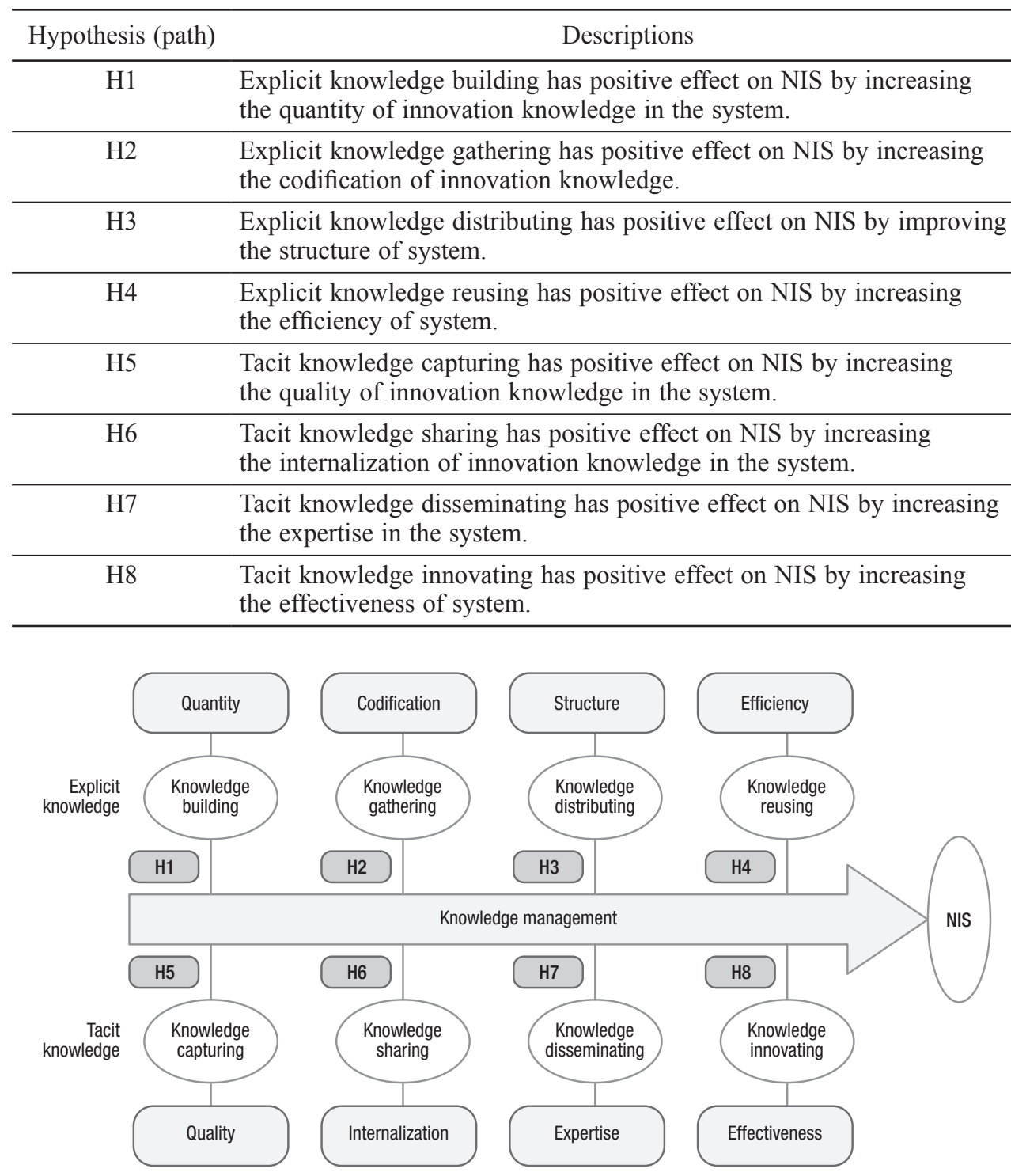

Fig. 1. Model of NIS enabled by KM

plicit knowledge and tacit knowledge. The former stresses on knowledge codification, while the latter emphasizes how knowledge workers share knowledge to facilitate tacit knowledge internalization. Explicit knowledge starts with building, and followed by gathering, distributing and reusing. There are particular key indicators to be reflected in each process as shown in the blue boxes on the top of Figure 1: quantity, codification, structure and efficiency. Explicit knowledge building as a knowledge management function affects NIS by increasing the quantity of innovation knowledge in the system. 
Explicit knowledge gathering as a knowledge management function affects NIS by increasing the codification of innovation knowledge. Explicit knowledge distributing as a knowledge management function affects NIS by improving the structure of system. Explicit knowledge reusing as a knowledge management function affects NIS by increasing the efficiency of system.

Likewise, tacit knowledge starts with capturing, and followed by sharing, disseminating and innovating. There are particular key indicators to be reflected in each process as shown in the blue boxes on the bottom of Figure 1: quality, internalization, expertise and effectiveness. Tacit knowledge capturing as a knowledge management function affects NIS by increasing the quality of innovation knowledge in the system, tacit knowledge sharing as a knowledge management function affects NIS by increasing the internalization of innovation knowledge in the system. Tacit knowledge disseminating as a knowledge management function affects NIS by increasing the expertise in the system. Tacit knowledge innovating as a knowledge management function affects NIS by increasing the effectiveness of system.

\section{Research methodology}

The aim of this study is to develop a conceptual model for showing how KM enables NIS. The investigation is focus on 1997-2014 particularly. Hence, based on literature we developed a conceptual model by which all the component of the model found its position in the model. In order to validate the model, we constructed a survey instrument to measure. To test the hypothesized relationships in the model was used a path analytic approach. The path analytic modeling involves using regression analysis to estimate the main path. Path analysis was used rather than structural equation modeling (SEM) because the sample size was relatively small. In addition, the model was relatively simple (Grapentine 2000).

\subsection{Data collection}

As said before, based on the prior literature, a questionnaire was designed to measure the model and CKO-class and R\&D practitioners in the macro and governmental level were sampled.

Questionnaire is an adopted instrument which has been selected for this research, because, questionnaires and surveys are structured ways of collecting data from a sample of a population. Questionnaires and surveys usually gather descriptive and normative data, though they can gather cause-and-effect data. Generally, they are useful for validating a grounded theory and are not good for exploring new ideas, therefore this instrument is adopted for our research. A great number of the sources were used to collect data, including interviews, observation, and examination of the documents and observation of the studied models. Further, the experts' views were used in this regard. These results again verified the convergence of the scale. The test on criterion validity was vital in examining the appropriateness of the data collected. The scale used Likert's 5-point scale (from $1=$ strongly disagree to $5=$ strongly agree). 
Respondents have been selected very carefully and they were participants in at least a $\mathrm{KM}$ and NIS project in national and macro level. 50 questionnaires were distributed and 45 valid copies were returned, making the response rate at $90 \%$. The profile of these subjects was $52 \%$ was female, and $25 \%$ under age $35,42 \%$ between 35 and 45 , and the remaining above 45 . The average employment duration of respondents spanned from under 5 years (17\%), 5-10 years (20\%), 11-15 (22\%), 16-20 (13\%), 21-25 (13\%), to more than 25 years $(15 \%)$. A majority of the respondents had university degree $(51 \%)$, followed by master's degree (33\%), vocational college degree $(11 \%)$, and doctoral degree $(4 \%)$.

\subsection{Data analysis}

Statistical techniques for data analysis and in order to analyze the collected results, we employed multivariate statistical techniques. The structural equation modeling approach is used in testing structural theory (Joreskog, Sorbom 1989). The maximum likelihood (ML) estimation method was employed. For this study, seven measures of goodness of fit were used, including GFI, AGFI, RMSR. Criterion validity of the scale was examined by testing the causality coefficients of LISREL. To test our hypotheses we run a series of regression analyses based on the questions of questionnaire. Path coefficient and tvalue are illustrated in Table 3.

Table 3. Path coefficient for the model

\begin{tabular}{ccc}
\hline Hypothesis & Path coefficient (standard coefficient) & t-value \\
\hline H1 & 0.22 & 6.46 \\
H2 & 0.32 & 5.45 \\
H3 & 0.46 & 5.78 \\
H4 & 0.33 & 5.43 \\
H5 & 0.23 & 4.08 \\
H6 & 0.34 & 4.87 \\
H7 & 0.41 & 4.67 \\
H8 & 0.33 & 4.56 \\
\hline
\end{tabular}

Path analysis is a straightforward approach of multiple regression calculations, which aims to provide estimates of the magnitude and significance of causal connections between a set of hypothesized variables. It is helpful to calculate the path coefficients so that their relationships can be identified if the variables have positive or negative impacts. The path coefficients drawn as Table 3 represents all of hypothesis have positive causal connections predicted earlier in this paper. All the outcomes of t-value also show high validation. For example, as set in H1, the increase of explicit knowledge building has positive influence on the quantity of knowledge management system in the context of NIS. 


\section{Results}

This study employed item-to-total correlations as indices to test the internal consistency and convergence of the model, the results are listed in Table 3. The coefficients for each hypothesis or path of framework, all of which matched the significance level requirement. The item-to-total correlation evidence indicated good convergence and internal consistency on the constructs.

\subsection{Reliability of the scale}

Cronbach was used to measure the inter-items consistency in the study. All sub-scales with a values ranged 0.87 , which implies the scale was reliable.

\subsection{Validity of the scale}

Only content validity was examined in the study. There were eight senior staff members with working experience from 10 to 25 years who pilot-tested the scale before administering the survey. Some of the items were modified and rephrased to consolidate the survey content.

\subsection{Construct validity}

A great number of the sources were used to collect data, including interviews, observation, and examination of the documents and observation of the studied models. Further, the experts' views were used in this regard. These results again verified the convergence of the scale. Structural equation model approach with help of the empirical evidence indicated marginal construct validity.

All parameter estimates in this model were large and also statistically significant, with a t-value greater than 1.96. Results indicated that the model fit the sample data well, with GFI $=0.999$. AGFI $=0.988$, RMSR $=0.006$.

Hence, the path coefficients drawn as Table 3 represents all of hypothesis have positive causal connections predicted earlier in this paper. All the outcomes of t-value also show high validation.

\section{Discussions}

The results obtained from the review of the different NIS approaches, the general KM model, allow the development of the new NIS approach from a systemic point of view. In summary, the research about the mechanisms of knowledge production and propagation, information disposition and knowledge sharing within all levels of national innovation system is still deficiency.

Since a large part of the previously analyzed approaches generally use similar indicators (i.e. capacity, effectiveness, efficiency, etc.), the main issue of the proposed approach (to stand out) is that it takes into account those indicators that allow the NIS performance with regard to explicit and implicit KM activities. Therefore, the scope of the proposal covers the KM processes and activities of those dimensions of NIS performance. 
According to the hypothesis the results of the research are as the following:

- Building of explicit knowledge increases the quantity of innovation knowledge in the system, which it means if the knowledge that has been articulated, codified, and stored becomes more the amount of innovation knowledge becomes more in the NIS.

- Gathering of explicit knowledge increases the codification of innovation knowledge in the system, which it means if the knowledge that has been articulated, codified, and stored becomes more it can be codified as the source of innovation knowledge in NIS.

- Distributing of explicit knowledge improves the structure of system which it means if the knowledge that has been articulated, codified, and stored becomes more it can be readily transmitted to others in the national innovation system as the source of innovation knowledge - Reusing of explicit knowledge increases the efficiency of system, which it means if the knowledge that has been articulated, codified, and stored be reuses in the NIS then the time or effort is well used in NIS.

- Capturing the tacit knowledge increases the quality of innovation knowledge in the system, which it means if the kind of knowledge that is difficult to transfer to another person by means of writing it down or verbalizing it be captured then the attribute or property of the system will be increased in NIS.

- Sharing of tacit knowledge increases the internalization of innovation knowledge in the system, which it means if the kind of knowledge that is difficult to transfer to another person by means of writing it down or verbalizing it be shared then the process of acceptance of a set of norms established by people or groups which are influential to the individual will be happened in NIS.

- Disseminating of tacit knowledge increases the expertise in the system, which it means if the kind of knowledge that is difficult to transfer to another person by means of writing it down or verbalizing it be disseminated the extensive knowledge or ability based on research, experience, or occupation and in a particular area of study in a person will be increased in NIS.

- Innovating by tacit knowledge be increases the effectiveness of system, which it means if the kind of knowledge that is difficult to transfer to another person by means of writing it down or verbalizing it be used for innovating the capability of producing a desired result will be increased in NIS.

The results obtained from the review of the different NIS approaches and KM, which has been done by Carayannis et al. (2000), Chuanqi (2001), Cohen and Levintal (1989), Cuiping (2008), Amidon (1997), Foray (1994), Helios and Hidalgo (2008), Xiwei and Stößlein (2010), Goh (2004), Liu (2005), Li (2009) allow the development of a new conceptual model in a systemic point of view.

\section{Conclusions}

Knowledge management is an essential participation in NIS construction, but the literature show, yet, studies of modeling how KM enables NIS is scarce and it needs to explore more. The authors proposed a systematic framework that views knowledge management 
processes as an efficient and effective means for NIS. The achievements demonstrate 10 distinctive NIS performance dimensions and the relationship with KM functions. The first layer includes explicit knowledge; the second, deals with tacit knowledge both with a complete knowledge management functions and processes. whereas the third includes NIS enablers items or performance dimension of NIS: quality, effectiveness, quantity, codification, structure, efficiency, internalization, expertise, effectiveness. Hence, the model shows the relationships between KM functions on increasing of NIS performance dimensions. Future examination of our approach in real life NIS is necessary to draw guidelines for detailed.

\section{References}

Amidon, D. M. 1997. Innovation strategy for the knowledge economy: the ken awakening. Newton, MA: Butterworth Heinemann. ISBN 978-0-7506-9841-2.

Aramburu, N.; Saenz, J.; Rivera, O. 2006. Fostering innovation and knowledge creation: the role of management context, Journal of Knowledge Management 10(3): 157-168.

http://dx.doi.org/10.1108/13673270610670920

Carayannis, E.; Alexander, J.; Ioannidis, A. 2000. Leveraging knowledge, learning, and innovation in forming strategic government-university-industry (GUI) R\&D partnerships in the US, Germany, and France, Journal of Technovation 20: 477-488.

http://dx.doi.org/10.1016/S0166-4972(99)00162-5

Chuanqi, H. 2001. Knowledge innovation: new focus of competition: front of second modernization. Beijing: Economic Management Press.

Cohen, W. M; Levintal, D. A. 1989. Innovation and learning: the two faces of R\&D, Economic Journal 49: 569-596. http://dx.doi.org/10.2307/2233763

Coombs, R.; Hull, R. 1998. Knowledge management practices and path-dependency in innovation, Research Policy 27(3): 237-253. http://dx.doi.org/10.1016/S0048-7333(98)00036-5

Cuiping, W. 2008. A review of research in knowledge management and information guarantee of national innovation system, Library and Information Service Journal 2: 203-205.

David, P. A.; Foray, D. 1994. Dynamics of competitive technology diffusion through local network structures: the case of EDI document standards, in L. Leydesdorff, P. Van den Besselaar (Eds.). Evolutionary economics and chaos theory: new directions in technology studies. London: Pinter Publishers, 63-78.

DTI. 1998. Our Competitive Future: Building the Knowledge Driven Economy. Technical report. Department of Trade and Industry. London.

Durant-Law, G. 2006. Knowledge management models or models of knowledge? A critical review of the literature. Canbera: The University of Canberra.

Foray, D. 1994. Production and distribution of knowledge in the new systems of innovations: the role of intellectual property rights, STI Review 14: 119-152.

Freeman, C. 1987. Technology and economic performance: lessons from Japan. London: Pinter Publishers.

Goh, A. 2004. University of South Australia, enhancing organizational performance through knowledge innovation: a proposed strategic management framework, Journal of Knowledge Management Practice October 2004.

Grapentine, T. 2000. Path analysis vs. structural equation modeling, Marketing Research 12(3): 12-20.

Grover, V.; Davenport, T. H. 2001. General perspectives on knowledge management: research agenda, Journal of Management Information Systems 18(1): 5-21. 
Guzman, A. C.; Wilson, J. 2005. The soft dimension of organizational knowledge transfer, Journal of Knowledge Management 9(2): 59-74. http://dx.doi.org/10.1108/13673270510590227

Hekkert, M. P.; Suurs, R. A. A.; Negro, S. O.; Kuhlmann, S.; Smits, R. E. H. M. 2011. Functions of innovation systems: a new approach for analysing technological change, Technological Forecasting an Social Change Journal 74: 413-432. http://dx.doi.org/10.1016/j.techfore.2006.03.002

Helina, M.; Vesa, H. 2008. Data, information and knowledge in regional innovation networks, European Journal of Innovation Management 11(1): 103-124.

http://dx.doi.org/10.1108/14601060810845240

Helios, V.; Hidalgo, A. 2008. Towards a national innovation system in México based on knowledge, The International Journal of Technology, Knowledge and Society 4(1):1832-366.

$\mathrm{Hu}, \mathrm{C}$; Cao, N.; Zhang, M. 2008. The transformation of information service and its development strategy for innovative nation, Journal of Shanxi University (Philosophy and Social Sciences Edition).

Jafari, M.; Akhavan, P.; Mortezaei, A. 2009. A review on knowledge management discipline, Journal of Knowledge Management Practice 10(1): 1-23.

Jolivet, E.; Laredo, P.; Shove, E. 2003. Managing breakthrough innovations: theoretical implications from the sociology of science and technology, in The ASEAT Conference Knowledge and Economic \& Social Change: New Challenged to Innovation Studies, 7-9 April 2003, Manchester, UK.

Joreskog, K. G.; Sorbom, D. 1989. LISREL 7 user's reference guide. New Jersey, NJ: Lawrence Erlbaum Associates.

Li, J. 2003. The effective organization mode of knowledge flow in national innovation system: knowledge alliances, Information Science 3: 266-268.

Li, W. 2009. A review of literature on knowledge information service for regional innovation system, in International Conference on Management and Service Science, 2009. MASS '09, 20-22 September 2009, Wuhan, China.

Liu, S. 2005. Study on knowledge intensive services in innovation system, Science of Science and Management of S.\&T 3: 61-65.

Liu, W.; Shi, Z. 2004. Knowledge management in national innovation system, Journal of Chongqing University (Social Science Edition) 3: 30-32.

Lundvall, B.-Å. 2006. Nation States, social capital and economic development - a system's approach to knowledge creation and learning, Working Paper 135. Research Center on Development and International Relations (DIR), Aalborg University.

Ma, S. 2004. A research on the functions of intermediary service of science and technology in national innovation system and the construction of the organization system, China Soft Science 1: 109-113, 120.

Meng, X. 2005. Information guarantee system construction supporting knowledge creation, Information and Documentation Services 3: 15-19.

Mytelka, L.; Smith, K. 2002. Policy learning and innovation theory: an interactive and co-evolving process, Research Policy 31: 1467-1479. http://dx.doi.org/10.1016/S0048-7333(02)00076-8 Nelson, R. R.; Winter, S. 1982. An evolutionary theory of economic change. Cambridge, MA: Harvard University Press.

Nelson, R. R.; Rosenberg, N. 1993. Technical innovation and national systems, in R. R. Nelson (Ed.). National innovation systems. a comparative analysis. New York: Oxford University Press.

Newman, B.; Conrod, K. W. 1999. A Frame Work for Characterizing Knowledge Management Method, Practices and Technologies [online], [cited 2002]. Available from Internet: http:// www.3-cities.com/ bonewman/newman_conrad\%20PAKM2000-16.pdf

Nonaka, I.; Takeuchi, H. 1995. The knowledge creating company: how Japanese companies create the dynamics of innovation. Oxford, UK: Oxford University Press. 
OECD. 1996. The knowledge-based economy. Technical report. Paris: OECD.

Patel, P.; Pavitt, K. 1994. The nature and economic importance of national innovation systems, STI Review 14: 9-32.

Peng, C. 2003. Obstacle and prescription for internal knowledge transmission of regional innovation system, Studies in Science of Science 1: 107-111.

Randeree, E. 2006. Knowledge management: securing the future, Journal of Knowledge Management 10(4): 145-156. http://dx.doi.org/10.1108/13673270610679435

Scalzo, N. 2006. Memory loss? Corporate knowledge and radical change, Journal of Business Strategy 27(4): 60-69. http://dx.doi.org/10.1108/02756660610677137

Thompson, N. A.; Herrmann, A. M.; Hekkert, M. P. 2014. How sustainable entrepreneurs engage in institutional change: insights from biomass torrefaction in the Netherlands, Journal of Cleaner Production. http://dx.doi.org/10.1016/j.jclepro.2014.08.011

Wang, B.; Kong, J. 2004. Information needs and information guarantee in national innovation system, Information Science 6: 657-659, 663.

Wang, C. 2002. Information guarantee construction of national innovation system, Information and Documentation Services 2: 12-15.

Xiao, X. 2004. Information guarantee model and operation mechanism of knowledge innovation, Journal of Foshan University (Social Science Edition) 1: 90-93.

Xiwei, W.; Stößlein, M. 2010. Designing knowledge chain networks in China - a proposal for a risk management system using linguistic decision making, Technological Forecasting \& Social Change 77: 902-915. http://dx.doi.org/10.1016/j.techfore.2010.01.002

Zander, U.; Kogut, B. 1995. Knowledge and the speed of transfer and imitation of organizational capabilities, an empirical test, Organization Science 6(1): 76-92.

http://dx.doi.org/10.1287/orsc.6.1.76

Zhao, G.; Zhao, L.; Xiong, L. 2004. Knowledge management in regional innovation system, Inquiry into Economic Problems 3: 42-44.

Zhao, B. 2003. On the information guarantee of intellectual innovation systems, Information Science 1: 10-14.

Mei-TAI CHU, Dr is currently Program Director of Master of Business Information Management Systems and Senior Lecturer of Department of Management, La Trobe Business School at La Trobe University. Her diverse research interests include Knowledge Management, Communities of Practice, Multi-agent Systems, Computational Intelligence, Expert Systems, Technology Management and Human Resource Management.

Sedigheh REZAEIAN FARDOEI is Professor, PhD, Payame Noor University, Tehran, Iran. She has authored numerous books and papers in international level. Research interests: knowledge management, national innovation systems, strategic management.

Hasan FALLAH is Assistant Professor, PhD, Payame Noor University. He has authored numerous books and papers in international level. Research interests: information system, economic activities.

Sepehr GHAZINOORY is Associate Professor, PhD, University of Tarbiat Modares, Tehran, Iran. He has authored numerous books and papers in international level. Research interests: national innovation systems, science and technology policy making.

Alireza ALIAHMADI is Associate Professor, $\mathrm{PhD}$, University of Scince. He has authored numerous books and papers in international level. Research interests: strategic management, national innovation systems. 